\title{
Stepping Ahead Towards Harmonious Passion: Mediating Role of Self-Compassion
}

\author{
M. Vinoth $\operatorname{Kumar}^{1} *$, Vidhya Shree. S.V ${ }^{2}$
}

\section{ABSTRACT}

Nothing great in the world has ever been accomplished without passion. Passion is the strong emotion with inherent behavioural tendencies that can be positive as long as reason underlies the behaviour and this can be either harmonious or obsessive in nature. Thus, this view of passion suggests that adaptive benefits will accrue when individuals are in control of their passion (i.e. Harmonious passion). Moreover Self-compassion is found to elicit increased desirable and productive intrinsic motivation and helps individual perceive any activity as enjoyable or engaging. Thus, the present study adds on as a stepping stone which aims at studying the mediating role of Self-compassion in the relationship between Intrinsic motivation and Harmonious passion by incorporating Correlational research design and maximum variation sampling method (type of purposive sampling) in drawing 120 samples of working emerging adults (experience 0 - 3 years). Standardized tools; Global motivation scale (Guay et. al 2003), Self-compassion scale (Raes et. al 2010), Passion scale (Vallerand et. al. 2003) were used. Statistical measures Mean, S.D, Pearson's Product Moment Correlation and Meditational analysis was used in assessing the data and obtaining the results. And the findings showed that there was a direct effect of 0.192 between Intrinsic Motivation and Harmonious Passion and indirect effect of 0.2793 between the same in presence of the mediating variable SelfCompassion. Thus, it can be concluded that self-Compassion mediates the relationship between Intrinsic Motivation and Harmonious Passion. Self-Compassion training during the initial period of work or even further will help individuals to develop and experience Harmonious Passion attributing to various positive aspects of individual's life.

Keywords: Intrinsic Motivation, Harmonious Passion, Self-Compassion, Emerging Adults.

\footnotetext{
${ }^{1}$ Assistant Professor, Department of Psychology, St. Agnes Centre for Post Graduate Studies \& Research, Mangalore, India

${ }^{2}$ M.Sc. Student, Department of Psychology, St. Agnes Centre for Post Graduate Studies \& Research, Mangalore. India

*Responding Author

(C) 2016 I V Kumar, V Shree; licensee IJIP. This is an Open Access Research distributed under the terms of the Creative Commons Attribution License (http://creativecommons.org/licenses/by/2.0), which permits unrestricted use, distribution, and reproduction in any Medium, provided the original work is properly cited.
} 


\section{Stepping Ahead Towards Harmonious Passion: Mediating Role of Self-Compassion}

"I am born different and unique". This anecdote universally defines every single individual. It is not just the saying but then all of us are in fact unique in our own ways. Since our early developmental stages we engage ourselves in one or the other task or activity. Indeed, individuals who wake up in the morning with a smile on their face "because today is basketball day," musicians who practice several hours per day in the hope of achieving excellence, and scientists who spend years researching a phenomenon all have a passion activity that makes their lives worth living. Passion can fuel motivation, enhance well-being, and provide meaning in everyday life (Vallerand et al. 2003). Spinoza (1632-1677) proposed that acceptable thoughts originated from reason whereas unacceptable thoughts derived from passion. People afflicted with passion experienced a kind of suffering, in line with the etymology of the word passion (from the Latin passio for suffering). Rene Descartes (1596 -1650) defined passion as defined as strong emotions with inherent behavioural tendencies that can be positive as long as reason underlies the behaviour has always fascinated the philosophers and researchers in psychology. But in its variant perspective, and also with lack of empirical supports when it comes to developing and experiencing harmonious or adaptive type of passion in particular it becomes important to have further researches adding on to existing literature. And in accordance to the same, few existing literature states there exists a relationship between Intrinsic Motivation; defined as behaviour that is driven by internal rewards and Harmonious Passion; experienced When people engage in activities and pursuits that are inherently enjoyable or aligned to their identity, they feel they have chosen these endeavours (Vallerand et.al, 2003). Furthermore the grounds in this area of research have come across with findings that self-compassion; defined as acting same way towards oneself when one is having a difficult time, failure and notice something one don't like about oneself (Neff, 2003) helped individual experience increased intrinsic motivation and thus making the activity they are engaged in more enjoyable.

Now when we look back on these processes, it seems as if most of us undergo the same path of development but then with different means. So if it is different means for different individual then there must be various things and factors that differentiate each of us. During the early developmental stages it would have been named as our personal likings and further turned to be our unique individualizedinterests (Gottfredson, 2005). Being more specific it's more the "Interest" that which helps and guides us in making important choices of our life; be it in personal, education, career, and so on. And if we try looking it in deeper sense everything we had done, doing, planned to do in future all these connects us with our interests or even can be termed as our "origin of choices" (Lent, Brown, \& Hackett, 1994). When the choices are made of our interests it gives a kind of satisfaction and so we follow the same pattern in making decisions and this may be beneficial until one completes his or her education even though there might have been some minor problems. Hence, till the period of late adolescence everything is somehow managed. But then later when one enters the transitional period of emerging adulthood then arises the confusions, problems etc., as it is the period where most of them begin their work life or start making career choices (Peterson, \& Seligman, 2004). As like earlier times career choices

(C) The International Journal of Indian Psychology, ISSN 2348-5396 (e)| ISSN: 2349-3429 (p) | 160 


\section{Stepping Ahead Towards Harmonious Passion: Mediating Role of Self-Compassion}

are also chosen based on the "interest" of the individual. But how far their decisions have been appropriate for them becomes a question because this developmental period is one of the crucial transitional periods in life. And it has always attracted researchers to understand its nature and contribution in fulfilling life's goal (Perrone, Sedlacek, \& Alexander, 2001; Roach, \& Sauermann, 2010). Arnett (2000) stated that emerging adults want a lot out of life - a job that's well paid and personally meaningful and a lasting bond with a partner. Many might be headed for disappointment, he says, nothing that most employers simply want someone who can get a job done and half of all marriages end in divorce. Adding to work life decision; Work plays an eminent part in individuals life be it to earn daily bread or to satisfy one's basic needs and wants. 'Work' is defined as an activity involving mental or physical effort done in order to achieve a result. From the famous saying that "The difference between a successful person and others is not a lack of strength, not a lack of knowledge, but rather a lack of will" it can be comprehended that interest and passion plays important role in one's life (Lombardi, 2002).Furthermore, Arnett (2000) describes the period following emerging adult is the young adulthood; It begins with the adoption of adult roles, such as marriage, parenthood, and a stable occupational path. (Late twenties through the thirties). Henceforth, only if there is a healthy development and growth during emerging adulthood at both personal and work life it will have an positive influence over the young adulthood and as well the further developmental stages. Pertaining to the first characteristic feature (i.e. Identity exploration), there flourishes the term "Interest". But due to the negative impact of instability, feeling in between over interest there can be chances of decline in interest or even create various problems. Whereas, from the past empirical evidences it can be concluded that interest can be manifested to "Passion" which will attribute in better work-life satisfaction and individual's wellbeing (Vallerand, 2012;Johri, \& Misra, 2014).Research studies shows that interest is manifested into passion by the means of evaluation of the activity and internalization of the representation of the activity in one of the core aspect of the self, namely one's identity (Deci, Vallerand, Pelletier, \& Ryan, 1991; Vallerand, Pelletier, Blais, Briere, Senecal, \&Vallieres, 1992; Vallerand, \& Blssonnette, 1992).

Many individuals feel passionate about their work. They enjoy their role. For many people, this passion can promote well-being and satisfaction with life. But, for other people, this passion can actually culminate in burnout and dissatisfaction (Vallerand, 2008, 2010). The dualistic model of passion can explain this observation. According to this model, some people experience harmonious passion. That is, they feel they have chosen to embark in this career or pursuit. Consequently, they also feel they can engage or disengage from this passion whenever they choose. Consistent with self-determination theory, this sense of choice tends to promote wellbeing. Other people, however, may experience obsessive passion (Mageau et al. 2011). They feel almost compelled to pursue this passion. That is, if they resist this passion, they feel they will experience negative consequences, such as a decline in their status or self-esteem (Mageau, \& Vallerand, 2007). Consequently, they cannot choose to disengage from this passion. Indeed, this passion may even conflict with their other needs or goals, ultimately compromising their 


\section{Stepping Ahead Towards Harmonious Passion: Mediating Role of Self-Compassion}

wellbeing. Indeed, many studies indicate that harmonious passion is positively associated, and obsessive passion is negatively associated, with various indices of wellbeing. These relationships tend to persist even after related states, such as commitment or work holism, are controlled (Vallerand, 2008). Vallerandet al. (2003) believed that passions "make life worth living" depends on the type of passion one has developed. That is, whether a passion will foster positive affect and healthy persistence depends on whether it is harmonious or obsessive. With respect to affective outcomes, Harmonious Passion should lead to greater positive affect and less negative affect than Obsessive Passion during task engagement. This is because the autonomous internalization of the activity leads the person to engage in the task in a more flexible manner and thus to experience task engagement more fully (Vallerandet al. 2007). Such a flexible form of activity engagement should facilitate better concentration and the experience of positive affect, absorption, and flow. Such is not the case for Obsessive Passion, because a controlled internalization breeds an internal compulsion to engage in the activity, leading to a more rigid and conflicted form of task engagement. Such pressured engagement should prevent the person from fully focusing on the task at hand and take away the positive affective outcomes that would normally be experienced (Vallerand et al. 2003; Vallerand, Paquet, Philippe, \& Charest, 2010).Furthermore, Harmonious Passion also contributes to the experience of positive affect and minimizes the experience of negative affect after task engagement. This is because with HP, people are in control of the activity. They can decide to engage or not in the activity and when. Consequently, very little conflict will exist between the passionate activity and other activities in the person's life. However, with Obsessive Passion, an internal compulsion leads the person to engage in the activity even when he or she should not, thus causing conflict between the passionate activity and participation in other tasks. The person may therefore experience negative emotional experience once engagement in the passionate activity is terminated (Vallerand et al. 2007). Finally, because Obsessive Passioncontrols the activity of the person, an individual is likely to experience negative affect when prevented from engaging in the activity. Indeed, because of the internal pressure to engage in the passionate activity, it is impossible to disengage fully from thoughts about the activity (Lalande et al. 2015). Thus, the person will be distracted when working on other activities because they were prevented from doing their passion. The person will feel frustrated and upset about not being able to engage in the passionate activity as well as from not being able to experience pleasure in the competing activities (Stenseng, 2008; Mageau, Carpentier, \& Vallerand, 2011; Stenseng, Rise, \& Kraft, 2011).

Even though three variables were closely and positively related past researchers were not found connecting all the three variables together.Thus the present study dealt in studying the relationship between Intrinsic motivation and Harmonious Passion in presence of the mediating variable Harmonious Passion and hence, making way for better understanding of development and experiencing of Harmonious Passion. The population comprised of working emerging adults as it is the transitional period where the individual has demographic diversity and 


\section{Stepping Ahead Towards Harmonious Passion: Mediating Role of Self-Compassion}

instability, reflecting the emphasis on change and exploration characterized by pervasive changes in autonomy, residence, identity, social roles and career pursuits (Arnett, 2004). Only when there exists a work-life satisfaction, it accounts for the smooth functioning of the individual in various areas of his or her life and hence, developing harmonious passion would help in having better life satisfaction and also psychological wellbeing (St-Louis, Carbonneau, \&Vallerand, 2016). Even though shaping of passion may occur during any age period, but then as most of the characteristic features of the age ranging from emerging to young adulthood holds the actual ground for healthy shaping of passion, and personality. Henceforth; Research in this population grabs more attention of the researchers as only few researches are done on this area of research and in India, hardly any empirical evidences are traced. From the past empirical evidences it is figured that there exists a well-established framework right from the individual's interest till his or her psychological adjustment and well-being. But then the important pathway towards harmonious passion is neither been discussed or studied until now. And also researchers in this area in India are comparatively very less and so it becomes an importance to study and understand this process further. Thus, this establishes the basic foundation or need to carry out

\section{METHODS}

\section{Sampling Design}

Present study has opted for Correlational research design. The researcher begins with the idea that there exists a significant relationship between the variables. For that, maximum variation sampling (a type of purposive sampling) method was implemented to collect samples. It is also known as heterogeneous sampling, used to capture wide range of perspectives relating to the interested area of the present study. People, pieces of data, events or units under the study may exhibit a wide range of attributes, behaviors, experiences, incidents, qualities, situations, and so forth. And the basic principle behind this type of sampling is to gain greater insights into a phenomenon by looking at it from all angles. Present study worked with an assumption that work sector, work environment, nature of the work, has no significant role in developing harmonious passion or adaptive type of passion. Meaning, passion can be developed and experienced by an individual who has interest towards the work, and also possess intrinsic motivation. And so the study has opted to consider people under different work sector (heterogeneous in nature).A sample of 120 emerging adults from different work sector from Bangalore and Mangalore were chosen.

\section{Materials Used}

\section{Intrinsic Motivation}

Global Motivation Scaleby Guay, Vallerand, \& Blanchard (2001) used to assess global motivation toward behaving in general in their life as a whole. There as 28 items (4 items for each of the 7 subscales) assessed on a 7-point likert scale range from " $7=$ strongly agree" to " $1=$ strongly disagree”. The high score represents the high motivation. The GMS has demonstrated high levels of construct and concurrent validity as well as internal consistency. Cronbach's 


\section{Stepping Ahead Towards Harmonious Passion: Mediating Role of Self-Compassion}

Alpha for the subscales ranged from 0.69 to 0.93 .In the present study, only 3 constructs such as "Intrinsic motivation - to know", "Intrinsic motivation - toward accomplishment", "Intrinsic motivation - to experience stimulation" were used. The scale has showed a reliability of .77, the consistency of intrinsic subscale showed a reliability of $.80, .79$ and .82 respectively.

\section{Self-compassion}

Self-compassion Scale by Raes, Pommier, Neff, \& Van Gucht(2011) used to measure the person's ability to hold one's feelings of suffering with a sense of warmth, connection and concern. The scale consisted of 12 items both positive and negative items with rating scale from 1 - 5; never to always (short version of 26 items scale) Self-Kindness Items: 2, 6,Self-Judgment Items: 11, 12, Common Humanity Items: 5, 10, Isolation Items: 4, 8, Mindfulness Items: 3, 7, Over-identified Items: 1, 9. Subscale scores are computed by calculating the mean of subscale item responses. The SCS-SF demonstrated adequate internal consistency (Cronbach's alpha 0.86 in all samples) and a near-perfect correlation with the long form SCS ( $r \geq 0.97$ all samples). Confirmatory factor analysis on the SCS-SF supported the same six-factor structure as found in the long form, as well as a single higher-order factor of self-compassion. The SCS-SF thus represents a reliable and valid alternative to the long-form SCS, especially when looking at overall self-compassion scores (Van Dam, Sheppard, Forsyth, \& Earleywine (2011).

\section{Passion Scale}

Passion scale by Vallerandet.al. (2003) used to measure passion in the workplace situation. It consists of 14 items distributed into two subscales harmonious passion and obsessive passion. response are given based on a likert type scale from $1-7$ where, " $1=$ not agree at all" and " 7 = very strongly agree". Reliability scores in the passion scale have ranged from 0.78 to 0.88 (Marsh et.al 2013). In the present study only the items assessing harmonious passion was used. Moreover, in the present study sample, the Cronbach's Alpha score $(\alpha=.93)$ ascertain the adequate reliability of the scale.

\section{RESULTS}

\section{Insert Table 1 about here}

Table 1 depicts the correlation results of the variables under study (Intrinsic motivation, selfcompassion and Harmonious passion). The table shows a positive and significant correlation between all the variables. Independent variable Intrinsic motivation has shown a significant correlation with the mediated variable self-compassion at 0.01 level $(r=.81)$. Intrinsic motivation, the independent variable has demonstrated a significant positive correlation with the dependent variable Harmonious passion at 0.01 significant level ( $r=.61)$.Mediating variable selfcompassion also has a significant correlation with the dependent variable at the 0.01 level $(r=.77$, $\mathrm{p}<0.01)$.

(C) The International Journal of Indian Psychology, ISSN 2348-5396 (e) | ISSN: 2349-3429 (p) | 164 
Insert Table 2 about here

Table 2 portraits the results of Mediation Analysis. The obtained F value 41.6715 for $\mathrm{df}(1,118)$ that tested the Regression Model of intrinsic motivation predicting self-compassion was found to be significant at .000 level. The obtained $\mathrm{R}^{2}$ value is .2610 . The coefficient value of intrinsic motivation predicting self-compassion (a) is .4791 and the standard error value for the same is .0742 which is significant at .000 levels. The self-compassion constant (i1) value is 17.5048 and the standard error value is 3.8507 which is significant at 0.000 level.

The obtained F value 139.0409 for $\mathrm{df}(2,117)$ that tested the Regression Model of intrinsic motivation predicting harmonious passion through self-compassion was found to be significant at 000 level. The obtained $\mathrm{R}^{2}$ value is 0.7039 . The coefficient value of self-compassion predicting harmonious passion directly (b) is 0.5204 and the standard error value for the same is .0453 which is significant at 0.001 levels. The coefficient value of intrinsic motivation predicting harmonious passion (c') is 0.1929 and the standard error value for the same is .0425 which is significant at .001 levels. The harmonious passion constant (i2) value is 9.7053 and the standard error value is 2.0561 which is significant at .001 level.

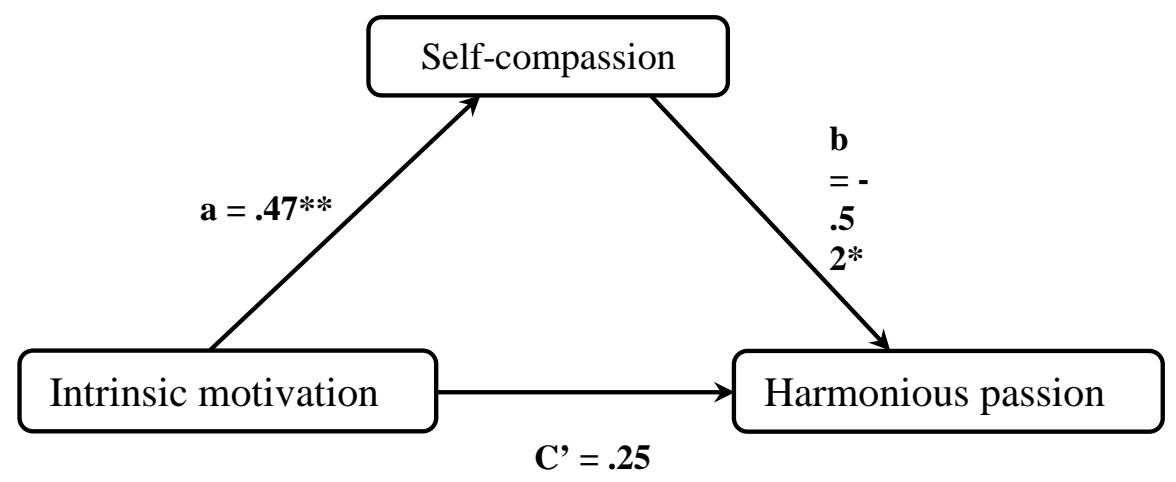

Fig 1. Standardized regression coefficients for the relationship between intrinsic motivation and harmonious passion as mediated by self-compassion.

The relationship between Intrinsic Motivation and Harmonious Passion was mediated by SelfCompassion. Figure 1 illustrates the standardized regression coefficient between Intrinsic Motivation and Self-Compassion was statistically significant, as was the standardized regression coefficient between Self-Compassion and Harmonious Passion. The standardized indirect effect was $(.47)(.52)=.2493$. The values were tested for the significance of this indirect effect using bootstrapping procedures. The bootstrapped unstandardized indirect effect was .2793. Thus, the indirect effect was statistically significant.

Rather than a direct causal relationship between the independent variable and the dependent variable, a mediation model proposes that the independent variable influences the (non-

(C) The International Journal of Indian Psychology, ISSN 2348-5396 (e)| ISSN: 2349-3429 (p) | 165 


\section{Stepping Ahead Towards Harmonious Passion: Mediating Role of Self-Compassion}

observable) mediator variable which in turn influences the dependent variable. Thus, mediator variable serves to clarify the nature of relationship between the independent and dependent variable. Thus accepting the hypothesis, Self-Compassion mediates the relationship between Intrinsic Motivation and Harmonious Passion among working emerging adults.

\section{DISCUSSION}

Passion has always fascinated the philosophers and researchers in psychology. But in its different perspective, and also because of lack of empirical support when it comes to developing and experiencing harmonious passion in particular. It has remained more like a question. Whereas, with further reading and reviews there was some link traced between Intrinsic Motivation, SelfCompassion and Harmonious Passion and also with regards to the population of emerging adults. Thus, the purpose of the study is, as mentioned before, to find out whether Self-Compassion mediates variable between Intrinsic Motivation and Harmonious Passion among working emerging adults. The primary objective was to assess the relationship between Intrinsic Motivation and Harmonious Passion, as there were only few research evidences stating a positive relationship between these variables especially when considered in India. Even the present study revealed that there was a significant positive relationship between these variables. The next objective of the study was to assess the mediating role of Self-Compassion in the relationship between Intrinsic Motivation and Harmonious Passion. This was totally based on the assumptions made on the basis of existing literature which stated that there exists a positive relationship between Intrinsic Motivation and Self-Compassion, Intrinsic Motivation and Harmonious Passion that, if an individual possess Intrinsic Motivation then it will attribute for his Harmonious Passion and more over if the individual also possess Self-Compassion along with Intrinsic Motivation then that can attribute in developing and experiencing Harmonious Passion at a greater level (Vinu, \& Vinothkumar, 2014). Moreover, introducing the mediating variable was again based on assumptions with regards to the common characteristics shared between Self-Compassion and Harmonious Passion, as there were research finding related to this area (Breines, \& Chen, 2012). The study findings show that Self-compassion mediates the relationship between Intrinsic Motivation and Harmonious Passion among working emerging adults. And thus, accepting the hypothesis stated. Mediation is an important effect caused through the variable Self-compassion. This also leads to a numerous implications with respect to the three variables. But before that, let us see how the mediation effect works with respect to this relationship between these variables. When the individual possess Intrinsic Motivation, according to this study he/she develops and experiences harmonious passion to a certain level. Thus, connecting to the previous point if he or she possesses Intrinsic Motivation along with Self-Compassion then they will develop and experience increased Harmonious Passion. Meaning as expected the results showed that the indirect effect that is effect of independent variable (Intrinsic Motivation) on dependent variable (Harmonious Passion) in presence of the mediating variable (Self-Compassion) was more by almost $70 \%$ when compared to that of direct effect of

(C) The International Journal of Indian Psychology, ISSN 2348-5396 (e) | ISSN: 2349-3429 (p) | 166 


\section{Stepping Ahead Towards Harmonious Passion: Mediating Role of Self-Compassion}

the independent variable (Intrinsic Motivation) on the dependent variable (Harmonious Passion) which was only $26 \%$.

As , there were no much existing literatures pertaining to that of developing and working on Harmonious Passion; this present study will not just add on to the literature but it has given a new path to help individuals develop and experience the adaptive type of passion.

Meaning, if the fresher's and the workers with minimum period of work experience are assessed for their level of Intrinsic Motivation and then trained with Self-Compassion training; then it will help them develop and experience the Harmonious Passion. This in turn will attribute to their work performance, pursuit of other opportunities, psychological adjustment and well-being. Apart from which, it becomes easier to overcome stress and burnout, neglect of alternative goals and moreover, work life can be balanced. And from existing literature we can say that job satisfaction will give rise to life satisfaction as well and henceforth, attributing to individual's existential fulfillment. Developing Harmonious Passion can even bring positive changes in the personality and thus increasing their intrapersonal and interpersonal relationships. And help in reaching the set goals, developing more effective skills, achieving one's standard is beneficiary to both the individual and the institution. This can even be applied in educational; vocational training set up like music schools, dance schools, chess school, sport training centers to enhance individual's Harmonious Passion. Moreover, Mindfulness-based Self- Compassion training is based on the Buddhist virtue of eastern perspective. Henceforth, applying this in eastern countries like India will bring in a lot of difference in the individual and individual's way of leading life (Brown, \& Ryan, 2003).If the signature strengths are identified and then the individual is helped to experience Harmonious Passion then it can help foster those signature strengths, like for example creativity can be fostered by experiencing Harmonious Passion.

On the whole, from the research finding of the present study; it can be stated that there is a wide range of areas where this can be applied and it can bring out drastic positive outcomes, not just to the individual but also related to his existence. And the present study becomes the stepping stone for further researches in this area.

\section{Acknowledgments}

The author appreciates all those who participated in the study and helped to facilitate the research process.

\section{Conflict of Interests}

The author declared no conflict of interests.

\section{REFERENCES}

Arnett, J. J. (2000). Emerging adulthood: A theory of development from the late teens through the twenties. American psychologist, 55(5), 469.

(c) The International Journal of Indian Psychology, ISSN 2348-5396 (e)| ISSN: 2349-3429 (p) | 167 


\section{Stepping Ahead Towards Harmonious Passion: Mediating Role of Self-Compassion}

Breines, J. G., \& Chen, S. (2012). Self-compassion increases self-improvement motivation. Personality and Social Psychology Bulletin, 38(9), 1133-1143.

Brown, K. W., \& Ryan, R. M. (2003). The benefits of being present: mindfulness and its role in psychological well-being. Journal of personality and social psychology, 84(4), 822.

Deci, E. L., Vallerand, R. J., Pelletier, L. G., \& Ryan, R. M. (1991). Motivation and education: The self-determination perspective. Educational psychologist, 26(3-4), 325-346.

Gottfredson, L. S. (2005). Using Gottfredson's theory of circumscription and compromise in career guidance and counseling. Career development and counseling: Putting theory and research to work, 71-100.

Guay, F., Vallerand, R. J., \& Blanchard, C. (2000). On the assessment of situational intrinsic and extrinsic motivation: The Situational Motivation Scale (SIMS). Motivation and emotion, 24(3), 175-213.

Johri, R., \&Misra, R. K. (2014). Self-Efficacy, Work Passion and Wellbeing: A Theoretical Framework. IUP Journal of Soft Skills, 8(4), 20.

Lalande, D., Vallerand, R. J., Lafrenière, M. A. K., Verner-Filion, J., Laurent, F. A., Forest, J., \&Paquet, Y. (2015). Obsessive Passion: A Compensatory Response to Unsatisfied Needs. Journal of personality.DOI: 10.1111/jopy.12229

Lent, R. W., Brown, S. D., \& Hackett, G. (1994).Toward a unifying social cognitive theory of career and academic interest, choice, and performance. Journal of vocational behavior, 45(1), 79-122.

Lombardi, V. (2002). What it takes to be\# 1. Running Press Book Publishers.

Mageau, G. A., \& Vallerand, R. J. (2007).The moderating effect of passion on the relation between activity engagement and positive affect. Motivation and Emotion, 31(4), 312-321.

Mageau, G. A., Carpentier, J., \& Vallerand, R. J. (2011).The role of self-esteem contingencies in the distinction between obsessive and harmonious passion. European Journal of Social Psychology, 41(6), 720-729.

Mageau, G. A., Vallerand, R. J., Charest, J., Salvy, S. J., Lacaille, N., Bouffard, T., \& Koestner, R. (2009). On the development of harmonious and obsessive passion: The role of autonomy support, activity specialization, and identification with the activity. Journal of Personality, 77(3), 601-646.

Perrone, K. M., Sedlacek, W. E., \& Alexander, C. M. (2001). Gender and ethnic differences in career goal attainment. The Career Development Quarterly, 50(2), 168-178.

Peterson, C., \& Seligman, M. E. (2004). Character strengths and virtues: A handbook and classification. Oxford University Press.

Raes, F., Pommier, E., Neff, K. D., \& Van Gucht, D. (2011). Construction and factorial validation of a short form of the self-compassion scale. Clinical psychology \& psychotherapy, 18(3), 250-255.

Roach, M., \& Sauermann, H. (2010). A taste for science? PhD scientists' academic orientation and self-selection into research careers in industry. Research Policy, 39(3), 422-434.

Stenseng, F. (2008). The two faces of leisure activity engagement: Harmonious and obsessive passion in relation to intrapersonal conflict and life domain outcomes. Leisure Sciences, 30(5), 465-481.

Stenseng, F., Rise, J., \& Kraft, P. (2011). The dark side of leisure: Obsessive passion and its covariates and outcomes. Leisure Studies, 30(1), 49-62.

St-Louis, A. C., Carbonneau, N., \& Vallerand, R. J. (2016). Passion for a Cause: How It Affects Health and Subjective Well-Being. Journal of personality, 84(3), 263-276.

(c) The International Journal of Indian Psychology, ISSN 2348-5396 (e)| ISSN: 2349-3429 (p) | 168 


\section{Stepping Ahead Towards Harmonious Passion: Mediating Role of Self-Compassion}

Vallerand, R. J. (2008). On the psychology of passion: In search of what makes people's lives most worth living. Canadian Psychology/ Psychologie Canadienne, 49(1), 1.

Vallerand, R. J. (2010). On emotion in sport: Theoretical and social psychological perspectives. Journal of sports and exercise psychology, 5(2), 197-215.

Vallerand, R. J. (2012). The role of passion in sustainable psychological well-being. Psychology of well-Being: Theory, research and practice, 2(1), 1-21.

Vallerand, R. J., \&Blssonnette, R. (1992). Intrinsic, extrinsic, and amotivational styles as predictors of behavior: A prospective study. Journal of personality, 60(3), 599-620.

Vallerand, R. J., Blanchard, C., Mageau, G. A., Koestner, R., Ratelle, C., Léonard, M., \& Marsolais, J. (2003). Les passions de l'ame: on obsessive and harmonious passion. Journal of personality and social psychology, 85(4), 756.

Vallerand, R. J., Paquet, Y., Philippe, F. L., \& Charest, J. (2010). On the role of passion for work in burnout: A process model. Journal of personality,78(1), 289-312.

Vallerand, R. J., Pelletier, L. G., Blais, M. R., Briere, N. M., Senecal, C., \& Vallieres, E. F. (1992). The Academic Motivation Scale: A measure of intrinsic, extrinsic, and amotivation in education. Educational and psychological measurement, 52(4), 1003-1017.

Vallerand, R. J., Salvy, S. J., Mageau, G. A., Elliot, A. J., Denis, P. L., Grouzet, F. M., \& Blanchard, C. (2007). On the role of passion in performance. Journal of personality, 75(3), 505-534.

Van Dam, N. T., Sheppard, S. C., Forsyth, J. P., \& Earleywine, M. (2011). Self-compassion is a better predictor than mindfulness of symptom severity and quality of life in mixed anxiety and depression. Journal of anxiety disorders, 25(1), 123-130.

Vinu, V., \& Vinothkumar, M. (2014).Self-compassion, intrinsic motivation, social connectedness in relation to perceived stress and academic performance. Periyar University Journal of Psychology. 1(2), 87-94.

\section{Tables}

Table 1 Mean SD, Correlation between Intrinsic motivation, Self-compassion, and Harmonious passion

\begin{tabular}{|c|l|c|c|c|c|c|}
\hline Sl.No & \multicolumn{1}{|c|}{ Variables } & Mean & SD & $\mathbf{1}$ & $\mathbf{2}$ & $\mathbf{3}$ \\
\hline $\mathbf{1}$ & Intrinsic motivation & 51.60 & 5.46 & - & & \\
\hline $\mathbf{2}$ & Self-compassion & 42.22 & 5.13 & $.81^{* *}$ & - & \\
\hline $\mathbf{3}$ & Harmonious passion & 41.63 & 3.97 & $.64^{* *}$ & $.77^{* *}$ & - \\
\hline
\end{tabular}

** Correlation is significant at the 0.01 level (2-tailed). 
Stepping Ahead Towards Harmonious Passion: Mediating Role of Self-Compassion

Table 2 Mediation analysis relating self-compassion as a mediating variable between intrinsic motivation and harmonious

\begin{tabular}{|c|c|c|c|c|c|c|}
\hline \multicolumn{7}{|c|}{ Consequent } \\
\hline \multicolumn{3}{|c|}{ Self-Compassion } & \multicolumn{4}{|c|}{ Harmonious Passion } \\
\hline Antecedents & Coefficient & SE & $\mathbf{P}$ & Coefficient & SE & $\mathbf{P}$ \\
\hline $\begin{array}{l}\text { Intrinsic } \\
\text { motivation }\end{array}$ & a 0.4791 & 0.0742 & 0.000 & 0.1929 & 0.0425 & 0.000 \\
\hline $\begin{array}{l}\text { Self- } \\
\text { compassion }\end{array}$ & - & - & - & 0.5204 & 0.0453 & 0.000 \\
\hline \multirow[t]{2}{*}{ Constant } & $\mathrm{i}_{1} 17.5048$ & 3.8507 & 0.000 & $\mathrm{i}_{2} 9.7053$ & 2.0561 & 0.000 \\
\hline & $\mathrm{R}^{2}=0.2610$ & & \multicolumn{4}{|c|}{$\mathrm{R}^{2}=0.7039$} \\
\hline F Value & $F(1,118)=41$ & $\mathrm{P}=.000$ & & $\mathrm{~F}(2,117)=13 \mathrm{~s}$ & $09 \quad \mathrm{P}=\mathrm{c}$ & 000 \\
\hline
\end{tabular}

How to cite this article: V Kumar, V Shree (2016), Stepping Ahead Towards Harmonious Passion: Mediating Role of Self-Compassion, International Journal of Indian Psychology, Volume 3, Issue 4, No. 56, ISSN 2348-5396 (e), ISSN: 2349-3429 (p), DIP: 18.01.016/20160304, ISBN: 978-1-365-23992-2

(c) The International Journal of Indian Psychology, ISSN 2348-5396 (e)| ISSN: 2349-3429 (p) | 170 